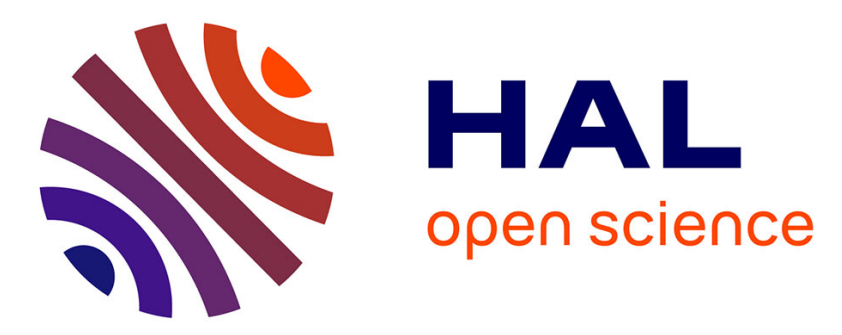

\title{
Optimal Standalone Data Center Renewable Power Supply Using an Offline Optimization Approach
}

\author{
Damien Landré, Jean-Marc Nicod, Christophe Varnier
}

\section{To cite this version:}

Damien Landré, Jean-Marc Nicod, Christophe Varnier. Optimal Standalone Data Center Renewable Power Supply Using an Offline Optimization Approach. Sustainable Computing - Informatics and Systems, 2021, 34, pp.100627 - 100634. hal-03549335

\section{HAL Id: hal-03549335 \\ https://hal.science/hal-03549335}

Submitted on 31 Jan 2022

HAL is a multi-disciplinary open access archive for the deposit and dissemination of scientific research documents, whether they are published or not. The documents may come from teaching and research institutions in France or abroad, or from public or private research centers.
L'archive ouverte pluridisciplinaire HAL, est destinée au dépôt et à la diffusion de documents scientifiques de niveau recherche, publiés ou non, émanant des établissements d'enseignement et de recherche français ou étrangers, des laboratoires publics ou privés. 


\title{
Optimal Standalone Data Center Renewable Power Supply Using an Offline Optimization Approach
}

\author{
Damien Landréa ${ }^{\text {, Jean-Marc Nicod }}{ }^{\mathrm{a}}$, Christophe Varnier ${ }^{\mathrm{a}}$ \\ ${ }^{a}$ FEMTO-ST institute, Université de Bourgogne Franche-Comté \\ CNRS / UFC / ENSMM, Besançon, France \\ [Damien.Landre, Jean-Marc.Nicod, Christophe.Varnier] @emto-st.fr
}

\begin{abstract}
Because of the increasing energy consumption of data centers and their $\mathrm{CO}_{2}$ emissions, the ANR DATAZERO2 project aims to design autonomous data centers running solely on local renewable energy coupled with storage devices to overcome the intermittency issue. In order to optimize the use of renewable energy and storage devices, a MILP solver is usually in charge of assigning the power to be supplied to the data center. However, in order to reduce the computation time and make the approach scalable, it would be more appropriate to use a polynomial time algorithm. This paper aims at showing and proving that it is possible to provide an optimal power profile via a deterministic algorithm using a binary search approach. Considering the main constraints of the initial problem, numerous experimental results show similar results to those given by the MILP. These promising results encourage us to continue in this direction for proposing an efficient management of the data center power supply that takes uncertainty into account.
\end{abstract}

Keywords: Green data center, Renewable energy, Power management strategy, Operational Research, Polynomial time algorithm.

\section{Introduction}

It is considered today that more than half of the world's population has access to the Internet [1], a network stored and managed by the data center. At the same time, these data centers represent $4.2 \%$ of the global energy consumption and $3.8 \%$ of $\mathrm{CO}_{2}$ emissions and it is estimated that these numbers is growing. Indeed, by 2025, it is estimated that the number of users will have increased by 1.1 billion, energy consumption will have multiplied by 2.9 and greenhouse gas emissions by 3.1 according to a World Digital Footprint Study [2].

Some projects such as GreenDataNet ${ }^{1}$ project [3] attempts to reduce the environmental impact by using $80 \%$ of the energy consumption in renewable energies and a smart energy management tool. The ANR DATAZERO ${ }^{2}$ project 4] goes much further because its goal is to design a data center running only on renewable energy and in an autonomous way. As renewable energies are intermittent, it is essential to combine these primary sources with secondary sources such as batteries (for the short term) and hydrogen (for the long term) in order to be able to meet customer demand, whatever the renewable energies provide.

1 http://www.greendatanet-project.eu/home.html

2 http://www.datazero.org
This autonomy could be studied and deepened thanks to real meteorological values (wind and solar irradiation) and a request from the customers, as well as real data on the various components that will integrate the data center. A sizing could thus be elaborated thanks to a statistical method to predict long-term wind speeds and solar irradiation and seems quite feasible [5], 6].

In order for the data center to be autonomous, we can manage the energy in an automated way. For this, 3 modules communicate with each other in order to determine the best profile that meets both customer demand and the power that can be supplied, while remaining reliable over time and during future profile negotiations: The Information Technology Decision Module (ITDM) for the computer system part ; The Power Decision Module (PDM) for the electrical part; And the Negotiation Module (NM) in charge of converging the 2 modules mentioned above towards a common profile and in accordance with their constraints [7, 4].

However, the electrical part provides a power profile thanks to a solver, and more precisely a Mixed Integer Linear Programming (MILP) known to have a computation time that can be exponential, especially since the number of variables and constraints, associated with the search for a power profile, is enormous. Thus, in order to save computation time and energy cost, it would be preferable to determine this power profile via another method than a solver like for example a deterministic algorithm (inas- 
much as the algorithm is not combinatorial, unlike MILP) with polynomial complexity.

The rest of this paper is organized as follows: In Section 2 we detail the related work. Section 3 provides the problem statement. Section 4 details the methodology of the deterministic algorithm in the non-constant case and Section 5 in the constant case. Section 6 gives a first approach when we integrate the battery self-discharge. Finally, we conclude and give some perspectives in Section 7 .

\section{Related work}

Currently the issue of using partial or total renewable energies such as wind and solar in order to power an area, a state, a region or data centers is becoming more and more common [8], 9], 10, [11. Due the intermittency of renewable energies, it seems essential to use energy storage element. However, some storage devices such as hydrogen or batteries are preferred for some uses over others, while seeking to maximize their life span [12], [13]. In order to use use renewable energies as much as possible instead of fossil energies, several methods and different approaches are implemented. For example, the use of renewable energies can be optimized as much as possible while respecting the constraints related to a good use of storage in order to extend their life span thanks to a solver or a simulation program [7], [13], [14]. It is also possible to look at the reduction of energy costs in the case of a hybrid energy system [8], [15], or in the case where only renewable energies is used with storage system by selling the over production of hydrogen to a neighboring state or for private hydrogen cars for example [10, 16. Ipsakis et al. in 17] deal with the online-optimization of the usage of energy storage for a constant load using a greedy algorithm. None of these works deals with the offline-optimization of the usage of energy storage for a constant and a non-constant demand on a large period of time using a polynomial time deterministic algorithm as shown in the following.

\section{Problem statement}

In our case, the ultimate goal is to have a sufficient amount of primary energy (renewable energy) and stored energy to ensure the autonomy of the data center while optimizing the costs, the use of these energy sources and the response to the demand. Using a deterministic algorithm is faster than using a MILP solver to find the best possible power profile. The main issue is to initiate the negotiation process mentioned above [18]. This step is a paramount step to match both the electric demand and supply. Other objectives have to be considered in the remaining steps of this negotiation [7, 19].

The input data and the variables of the addressed problem are respectively defined in Table 1 and in Table 2. We

\begin{tabular}{|c|c|}
\hline \multicolumn{2}{|r|}{ Renewable energy production } \\
\hline$P w t_{k}$ & wind turbine power production $[k W]$ \\
\hline$P p v_{k}$ & solar panel power production $[k W]$ \\
\hline \multicolumn{2}{|r|}{ Electrolyzers } \\
\hline$\eta_{e z}$ & Efficiency \\
\hline Pezmin & Minimum power $[k W]$ \\
\hline Pezmax & Maximum power $[k W]$ \\
\hline \multicolumn{2}{|r|}{ Fuel cells } \\
\hline$\eta_{f c}$ & Efficiency \\
\hline Pfcmin & Minimum power $[k W]$ \\
\hline Pfcmax & Maximum power $[k W]$ \\
\hline \multicolumn{2}{|r|}{ Batteries } \\
\hline$\eta_{c h}$ & Charge efficiency \\
\hline$\eta_{d c h}$ & Discharge efficiency \\
\hline Pchmax & Max charge power $[k W]$ \\
\hline Pdchmax & Max discharge power $[k W]$ \\
\hline$S O C \max$ & Max state of charge $[\%]$ \\
\hline SOCmin & Min state of charge [\%] \\
\hline SOCinit & Initial state of charge [\%] \\
\hline$C_{\text {bat }}$ & Capacity $[k W h]$ \\
\hline$\sigma$ & Self-discharge rate \\
\hline \multicolumn{2}{|r|}{ Hydrogen } \\
\hline$\eta_{\text {tank }}$ & Tank efficiency \\
\hline LOHinit & Initial hydrogen level $[k g]$ \\
\hline LOHtarget & Target hydrogen level $[\mathrm{kg}]$ \\
\hline$L O H \max$ & Max level $[k g]$ \\
\hline$H H V h_{2}$ & Higher Heating Value $\left[k W h . \mathrm{kg}^{-1}\right]$ \\
\hline$L H V h_{2}$ & Lower Heating Value $\left[k W h . k^{-1}\right]$ \\
\hline \multicolumn{2}{|r|}{ Others parameters } \\
\hline$\eta_{\text {inv }}$ & Inverter efficiency \\
\hline $\mathcal{H}$ & A given time window \\
\hline$\Delta t$ & Interval of time between two time steps \\
\hline$k$ & Index for one time setp within $\mathcal{H}$ \\
\hline$K$ & Number of time steps within $\mathcal{H}$ \\
\hline
\end{tabular}

Table 1: Input data of the optimization problems

take another look at the problem posed by the article [7]. The idea is to maximize power to be delivered to the data center noted:

$$
\operatorname{Pprod}_{k}, \forall k \in \llbracket 0, K-1 \rrbracket
$$

With $K$ the number of time steps within the time horizon $\mathcal{H}=K \Delta t$. It is possible to provide a non-constant power profile (Equation (1)) or a constant power profile (Equation (2)):

$$
\operatorname{Pprod}_{k}=\text { Pprod }, \forall k \in \llbracket 0, K-1 \rrbracket, \operatorname{Pprod} \in \mathbb{R}
$$

The data center can be powered by wind turbines, photovoltaic panels (depending on weather conditions) and by energy from storage systems like batteries and hydrogen 


\begin{tabular}{|c|c|}
\hline \multicolumn{2}{|r|}{ Output objectives } \\
\hline Pprod $_{k}$ & $\begin{array}{l}\text { Objective to maximize for the non-constant } \\
\text { case (Eq (1)) }\end{array}$ \\
\hline Pprod & $\begin{array}{l}\text { Objective to maximize for the constant case } \\
\text { (Eq (2)) }\end{array}$ \\
\hline \multicolumn{2}{|r|}{ Variables concerning batteries } \\
\hline$P c h_{k}$ & $\begin{array}{l}\text { Charging power of the batteries during time } \\
\text { slot } \mathrm{k}[k W]\end{array}$ \\
\hline$P d c h_{k}$ & $\begin{array}{l}\text { Discharging power of the batteries during the } \\
\text { time slot } \mathrm{k}[k W]\end{array}$ \\
\hline$S O C_{k}$ & $\begin{array}{l}\text { State of charge of the batteries at instant } k \Delta t \\
{[\%]}\end{array}$ \\
\hline \multicolumn{2}{|r|}{ Variables concerning Hydrogen system } \\
\hline$P e z_{k}$ & $\begin{array}{l}\text { Charging power of electrolyzers during time } \\
\text { slot } k[k W]\end{array}$ \\
\hline$Q e z_{k}$ & Electrolyzers $H 2$ mass during time slot $\mathrm{k}[\mathrm{kg}]$ \\
\hline$P f c_{k}$ & $\begin{array}{l}\text { Discharging power of fuel cells during time slot } \\
\mathrm{k}[k W]\end{array}$ \\
\hline$Q f c_{k}$ & Fuel cells $H 2$ mass during time slot $\mathrm{k}[\mathrm{kg}]$ \\
\hline$L O H_{k}$ & $\begin{array}{l}\text { Level of } \mathrm{H} 2 \text { in the tank at the end of the time } \\
\text { slot k with } \mathrm{LOH}_{0}=L O H \text { init }[\mathrm{kg}]\end{array}$ \\
\hline
\end{tabular}

Table 2: Variables of the optimization problems

depending on whether we have a surplus or a lack of energy produced by the primary sources. So, $\forall k \in \llbracket 0, K-1 \rrbracket$, we have in Equation (3):

$$
\begin{aligned}
& \operatorname{Pprod}_{k} \leq P w t_{k}+P p v_{k}+ \\
& \left(P f c_{k}+P d c h_{k}-P e z_{k}-P c h_{k}\right) \times \eta_{i n v}
\end{aligned}
$$

With $P w t_{k}+P p v_{k}=P r e_{k}$ the power supplied by renewable energies at time $k$. $P w t_{k}$ and $P p v_{k}$ represent the power respectively produced by wind turbines and photovoltaic panels at time $k . P f c_{k}$ and $P d c h_{k}$ are the power supplied by fuel cells from hydrogen and batteries at time $k$ and $P e z_{k}$ and $P c h k$ the charging power of hydrogen tanks and batteries. On these variables, we have to respect the following constraints, $\forall k \in \llbracket 0, K-1 \rrbracket$ :

$$
\left\{\begin{array}{l}
0 \leq P c h_{k} \leq P c h \max \\
0 \leq P d c h_{k} \leq P d c h \max \\
0 \leq P f c_{k} \leq P f c \max \\
\text { Pezmin } \leq P e z_{k} \leq \text { Pezmax }
\end{array}\right.
$$

The battery state of charge is limited by the SOC range (SOCmin and SOCmax) with $k \in \llbracket 0, K \rrbracket$ and depends both on the charge and discharge phases. Similarly, the level of hydrogen is limited by the $\mathrm{LOH}$ range ( 0 and $L O H \max$ ) with $k \in \llbracket 0, K \rrbracket$ :

$$
\begin{aligned}
& \left\{\begin{array}{l}
\text { SOCmin } \leq S O C_{k} \leq S O C \max \\
S O C_{k}=S O C_{k-1}(1-\sigma) \\
\quad+\frac{P c h_{k-1} \Delta t \times \eta_{c h}-P d c h_{k-1} \Delta t / \eta_{d c h}}{C b a t} \\
\text { SOCinit }=S O C_{0}
\end{array}\right. \\
& \left\{\begin{array}{l}
0 \leq L O H_{k} \leq L O H \max \\
P e z_{k} \Delta t=H H V h_{2} \times Q e z_{k} / \eta_{e z} \\
P f c_{k} \Delta t=L H V h_{2} \times Q f c_{k} \times \eta_{f c} \\
L O H_{k}=L O H H_{k-1}+Q e z_{k-1}-Q f c_{k-1} / \eta_{t a n k} \\
L O H i n i t=L O H_{0}
\end{array}\right.
\end{aligned}
$$

But this search for profile is subject to various constraints on storage to ensure the data center a certain availability for the following days, because of the intermittency of the primary energies. For example, one may want the hydrogen level to reach a certain target level over the time horizon $\mathcal{H}$ (LOHtarget), and at the same time, the batteries must be able to ensure a return to their initial level at the end of the time horizon [19]. Moreover at the end of each day, the batteries must return to its initial level to ensure the next day by supplying in part the data center when the primary energy lacks:

$$
\left\{\begin{array}{l}
L O H_{K} \geq \text { LOHtarget } \\
S O C_{k} \geq S O C \text { init if } k \equiv 0 \quad(\bmod 24) \\
S O C_{K}=S O C \text { init }
\end{array}\right.
$$

In addition, charging and discharging batteries at the same time, using electrolyzers and fuel cells at the same time, or discharging batteries to charge hydrogen using electrolyzers and discharging hydrogen using fuel cells to charge batteries is prohibited.

Knowing this, the problem tackled by the paper is to provide an optimal solution, i.e., by maximizing $\operatorname{Pprod}_{k}, \forall k$ or Pprod, while respecting the constraints of the problem.

\section{Deterministic algorithm in the non-constant case}

In this part, we assume that $\sigma=0$ (see Equation (5p) and Pezmin $=0$ (see Equation (4)). In the non-constant case, where the purpose is to maximize $\operatorname{Pprod}_{k}, \forall k$ (see Equation (1)), and where we want to provide the data center with energy according to what the renewable energies provide, it is enough to take $\forall k, \operatorname{Pprod}_{k}=\operatorname{Pre}_{k}$, as shown in Figure 1, with $\operatorname{Pre}_{k}=P w t_{k}+P p v_{k}$ the power supplied by renewable energy at time $k$ and $\operatorname{Pprod}_{k}$ the power to be supplied to the data center at time $k$.

In the case we want to charge with hydrogen, in order to reach the targeted level of hydrogen at the end of the resolution period, we just need to cut the top off the higher 


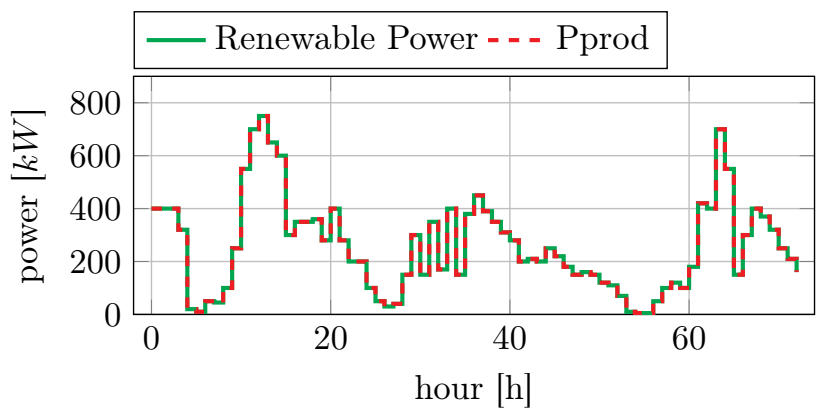

Figure 1: Energy attribution in the non-constant case

values, as explained in Figure 2. Inversely, in the case we want to discharge from hydrogen, in order to reach the targeted level of hydrogen at the end of the resolution period, we just need to cut the bottom off the smaller values, as shown in Figure 3 .

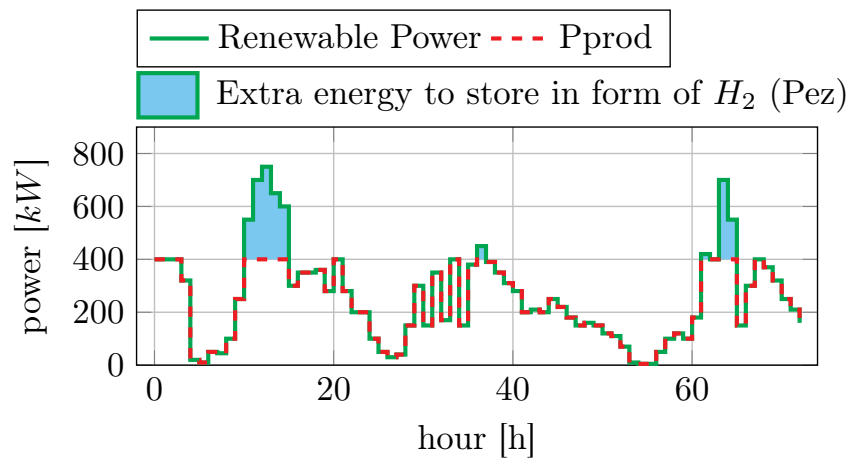

Figure 2: Energy attribution in the non-constant case with hydrogen charging

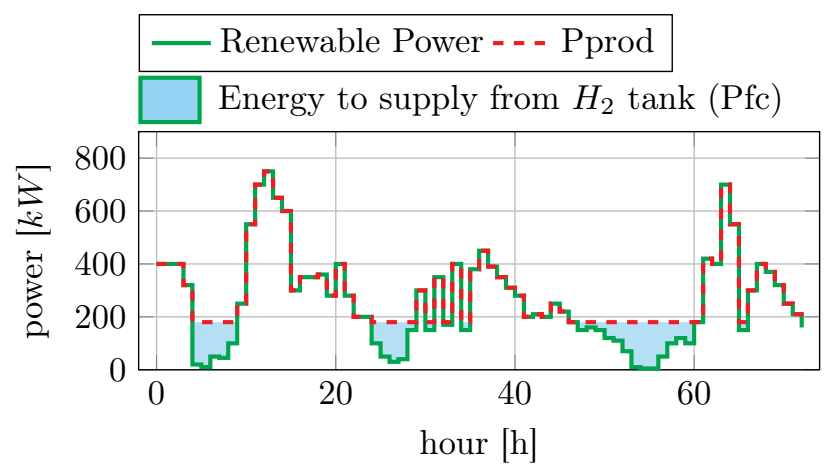

Figure 3: Energy attribution in the non-constant case with hydrogen discharging

As we can see, in all cases, the batteries is not used, we have $P c h_{k}=0$ and $P d c h_{k}=0, \forall k \in \llbracket 0, K-1 \rrbracket$ in Equation (3). And since we do not take the battery selfdischarge into account, we have ensured that the constraint on the batteries which stipulates that their state of charge must return to its initial state of charge at least every 24 hours is respected (see Equation (5) and 6).

\section{Deterministic algorithm in the constant case}

In this part, we consider $\sigma=0$ in Equation (5) and Pezmin $=0$ in Equation (4).

\subsection{How the algorithm works: Allocation part}

The algorithm starts by testing a solution previously determined using a binary search approach. It then performs hourly energy distribution (charging/discharging batteries and/or hydrogen) depending on weather conditions, the power delivered by the renewable energy is greater or less than what is needed to supply the data center. However, different problems can be encountered when allocating the energy. In this case, solutions are proposed by the algorithm to overcome these problems. Different situations are illustrated and explained by the figures in order to understand how the algorithm works, then the criteria to lead the binary search algorithm to run the next problem to test.

A first problem of energy allocation during a day appears when the battery state of charge at the end of the day is lower than the initial battery level (see Equation (6)), as shown on the left side of Figure 4. Here, the energy is distributed over the first 24 hour period, with the batteries being the most efficient devices (better efficiency than electrolyzers). We notice that at the end of the day, the state of charge of batteries is lower than its initial level. To overcome this problem (on the right side of Figure 4), we evaluate the difference between the targeted level at the end of 24 hours (at least the initial level) and the level obtained (which is lower than the initial level), and this difference is canceled out by supplying it from hydrogen. We therefore carry out a redistribution of energy and we can now see that by taking the difference in hydrogen, at the end of 24 hours, batteries level equals at least their initial level.

A second energy allocation problem that can be encountered during a day is the fact of wanting to charge or discharge batteries when one of the charging or discharging limits is reached, as shown on the left side of Figure 5. and Equation (5) where the battery bounds are not respected. The energy is distributed over the first 24 hour period, always giving priority to the batteries. Here, we notice that after 6 hours, the battery state of charge has reached its minimum level (SOCmin). If we continue, this level of charge will be negative since from hour 6 to hour 12 , we must still discharge. As the minimum battery level is reached at hour 6 , it is no longer possible to discharge batteries. We therefore discharge hydrogen. As soon as it is possible to charge, the batteries will be favored again, which is the case from hour 12 to hour 18. Finally, at the end of the day, we check that the battery state of charge at least equals to its initial level, which is the case here. There is therefore no redistribution to be carried out over this first 24 hour period (see the right side of Figure 5). 

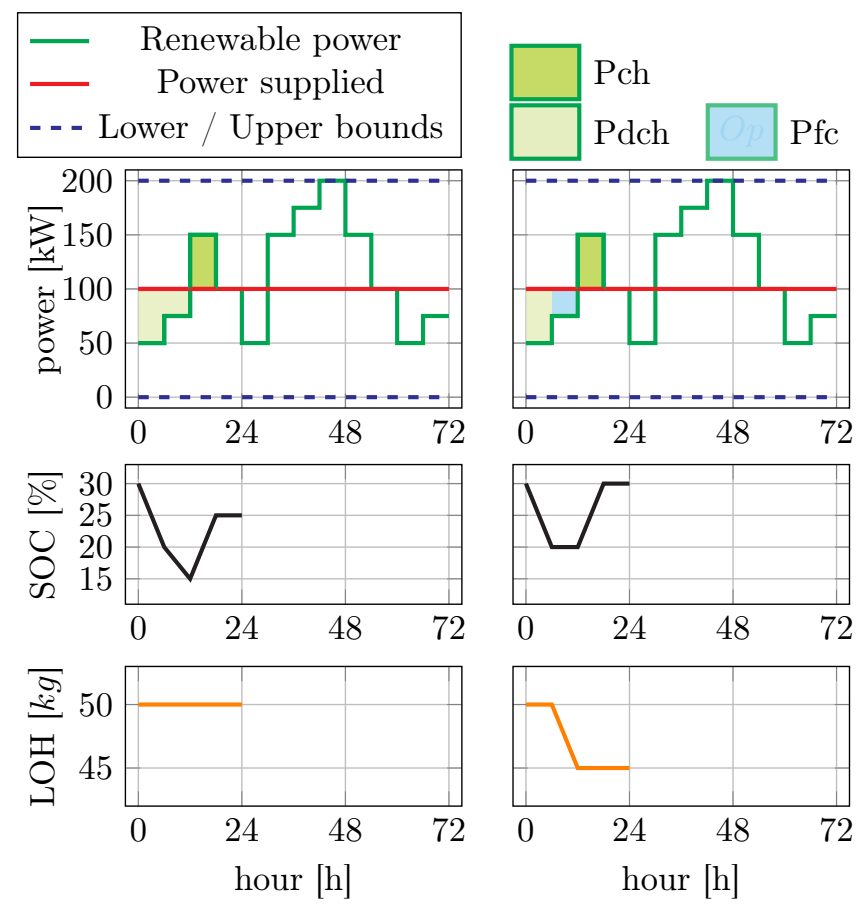

Figure 4: Left: battery level problem at the end of the first day. Right: Solution by discharging $\mathrm{H}_{2}$

This reasoning is equivalent in the case where the maximum battery state of charge is reached.
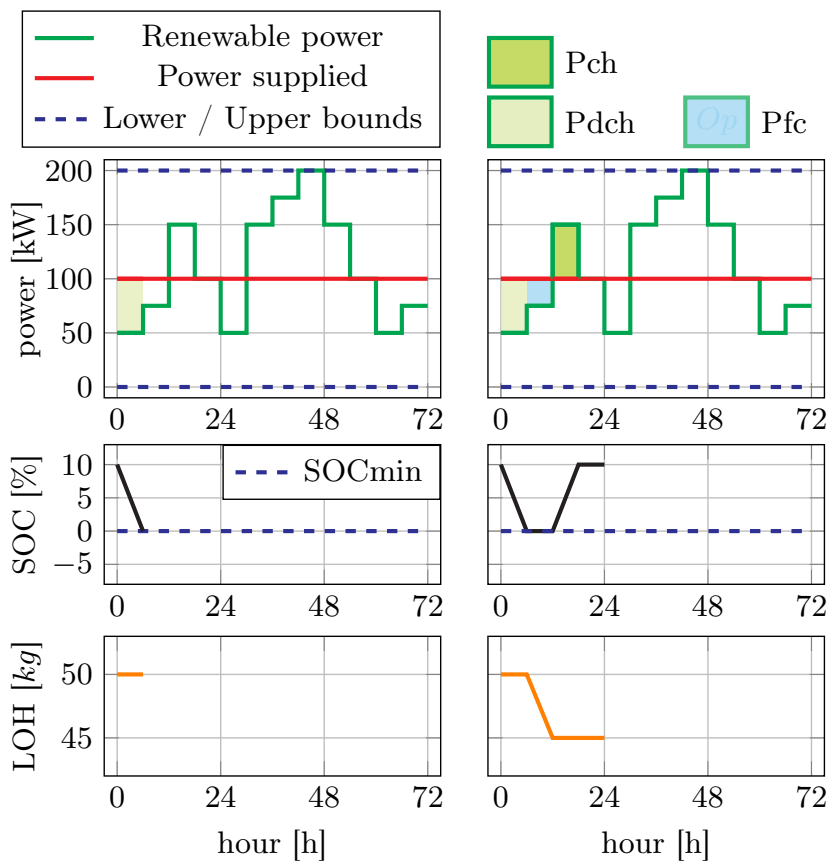

Figure 5: Left: Problem of attribution at the level of the battery charge. Right: Solution by discharging $\mathrm{H}_{2}$

A third energy allocation problem that can occur during a day is when the storage is no longer sufficient, as shown on the left side of Figure 6, and according to Equations (5) and (6) on the bounds of the batteries and hy-

drogen. The energy is distributed over the first 24 hours. During the first 6 hours, we notice that the batteries will not be able to ensure the lack of energy. So we complement energy production with hydrogen. However, at the end of the 6th hour, batteries and hydrogen are completely discharged, while we still need to discharge from hour 6 to hour 12. If we continue to discharge the batteries, we will exceed its minimum state of charge and its level will be negative. The same thing happens with hydrogen. We are in an extreme case where we have to conclude that this solution is not valid, and therefore not optimal, because it is too energy consuming with respect to our storage. In this case, the iteration ends and we now test with a lower power to be supplied to the data center, using a binary search algorithm. Here, on the right side of the same figure, the power to be supplied Pprod $=50 \mathrm{~kW} \cdot \mathrm{h}^{-1}$ and, at the end of the period, we notice that the allocation of energy has been successful and that there is no need to perform a redistribution, the battery state of charge being at least equal to its initial level. This reasoning is equivalent in the case of reaching the maximum level of batteries and hydrogen, in this case increasing the Pprod (the power to be supplied) because it is too pessimistic.
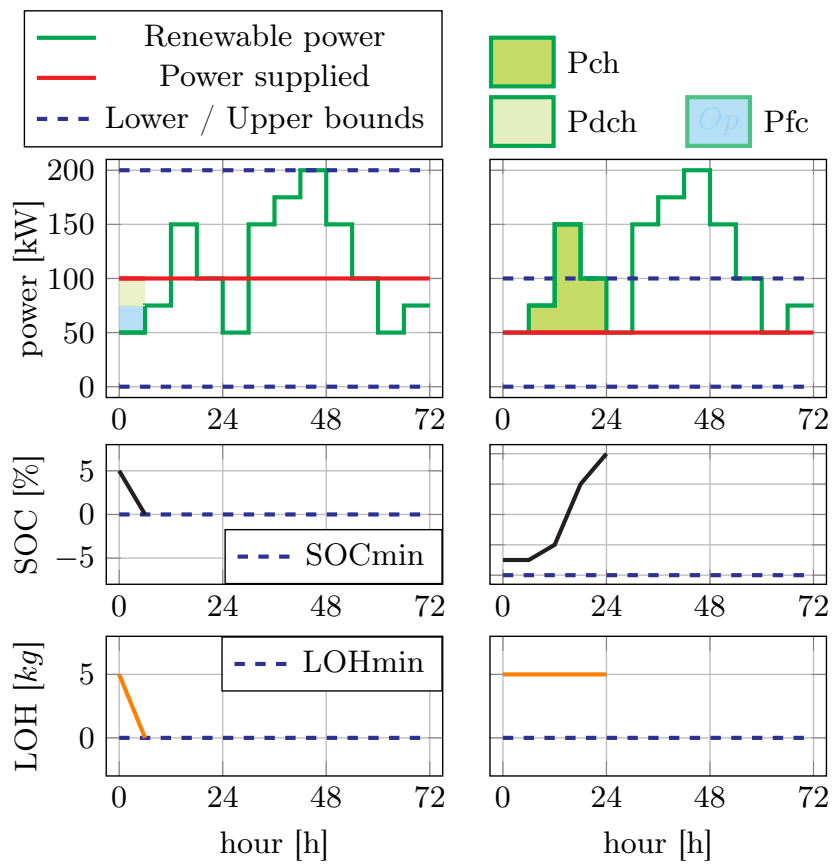

Figure 6: Left: Lack of energy in storage. Right: Solution by choosing a lower Pprod

Finally, a fourth problem is the surplus of energy in the batteries at the end of the resolution period (here 3 days), as shown on the left side of Figure 7. Therefore, a redistribution of energy is performed at the end of the 72 hour period. In this example, the energy is allocated over the entire 72 hour period, paying attention to the various problems that can arise as we have seen previously and respecting the fact that the battery state of charge must return to at least its initial level at the end of each 
day. We can see that at the end of the 72 hour period, the battery state of charge is much higher than initially. This energy excess in the batteries could be transferred into hydrogen, because of the constraint in Equation (6). We therefore redistribute the energy so that at the end of the 72 hour period the battery state of charge is equivalent to the initial state of charge. This surplus is then charged in hydrogen (see the right side of Figure 7).
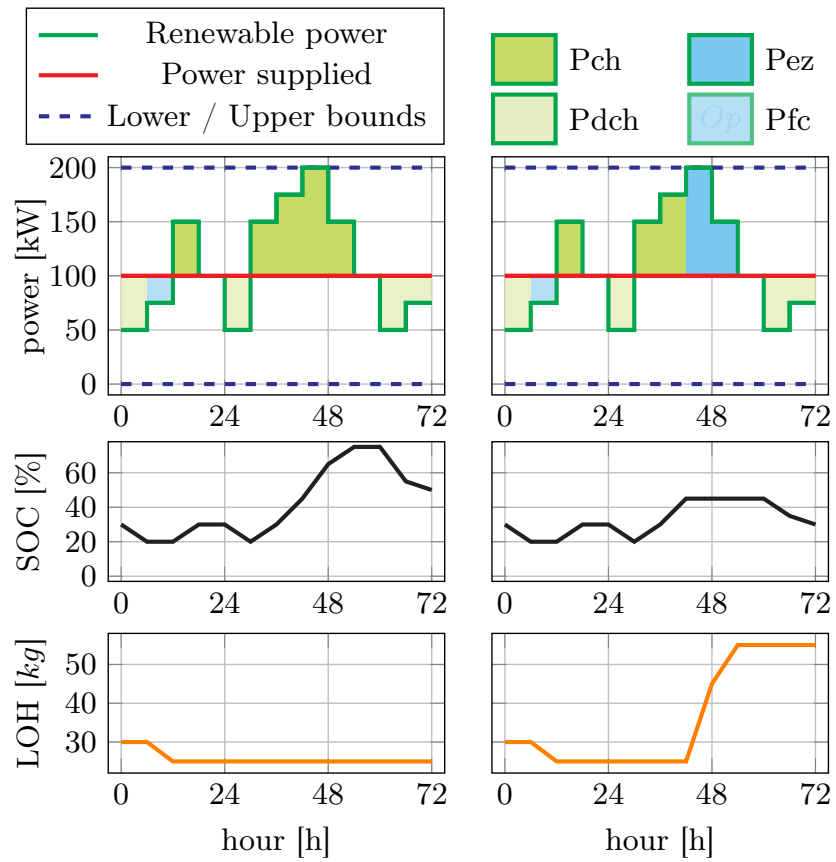

Figure 7: Left: Surplus in batteries at the end of the resolution period. Right: Reallocation of the energy in $\mathrm{H}_{2}$

The final level of hydrogen is checked (Figure 8). If the quantity of hydrogen obtained at the end of the 72 hour period is lower than the quantity of hydrogen which one wishes to have (i.e., LOHtarget), then one restarts an iteration by decreasing the power to be provided in order to charge more energy and thus to reach the desired quantity as explained by Equation (6), provided that the difference between the two bounds of the binary search algorithm is always greater than the approximation error $\epsilon$. Otherwise, we stop. Otherwise, if the amount of hydrogen obtained at the end of the 72 hour period is greater than the desired amount of hydrogen (LOHtarget), then we restart an iteration by increasing the power to be supplied to the data center in order to charge less energy and thus to meet the desired amount of hydrogen LOHtarget.

\subsection{Binary search approach}

So that the algorithm tests a solution as shown previously, it is necessary before all to provide it one: this one is determined beforehand using a binary search algorithm. We start by defining our upper bound (by taking the maximum provided by the renewable energies) and
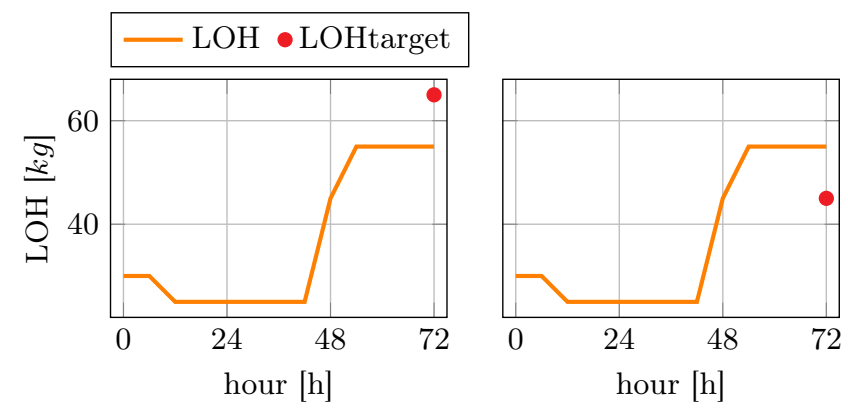

Figure 8: Solution change criterion for the binary search algorithm (comparison between the desired and the obtained hydrogen level, LOHtarget and $\mathrm{LOH}_{72}$ )

lower bound (by taking 0 ) between which the optimal solution lies. Then, we begin the first iteration of the binary search by testing the following solution $(\mathrm{Eq}(7))$ :

$$
\text { Pprod }=\frac{\max _{k \in \llbracket 0, K-1 \rrbracket}\left(\operatorname{Pre}_{k}\right)+0}{2}=\frac{200}{2}=100 \mathrm{~kW}
$$

This approach is illustrated in Figure 9

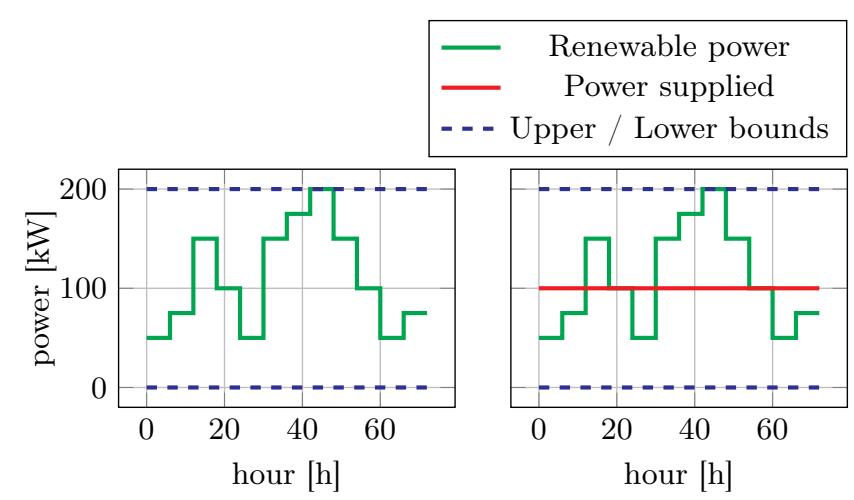

Figure 9: Definition of upper and lower bounds (200 and 0) for the binary search algorithm (Left) and first tested solution Pprod = $100 \mathrm{~kW}$ (Right)

Then, through different criteria defined after, the binary search algorithm provides a new solution to test:

- Lack of energy in storage devices: in this case, the upper bound becomes the current solution which is not valid because of the lack of energy in storage devices because the optimal solution cannot be beyond this one since electricity demand is higher than renewable energy supply. The new demand Pprod is then lower for the next iteration of the binary search algorithm.

- Surplus of energy in storage devices: in this case, the lower bound becomes the current solution which is not valid because of the surplus of energy in storage devices because the optimal solution cannot be below this one since electricity demand is 
lower than renewable energy supply. The new demand Pprod is then higher for the next iteration of the binary search algorithm.

- $\mathrm{LOH}_{K}<$ LOHtarget: In this case, the upper bound becomes the current solution in order to test at the next iteration a lower solution, which allows to charge more in hydrogen and thus approach the optimal Pprod.

- $\mathrm{LOH}_{K}>$ LOHtarget: In this case, the lower bound becomes the current solution in order to test at the next iteration a higher solution, which allows to discharge more hydrogen and thus approach the optimal Pprod.

The binary search algorithm stops by returning the solution that maximizes the objective function when the difference between the two bounds is lower than the error of approximation $\epsilon$ that we determine before the launching of the algorithm. The complexity of the algorithm that considers one value of Pprod is $O(K)$. Thus the complexity of the whole method is $O\left(K \log _{2}\left(\max _{k \in \llbracket 0, K-1 \rrbracket}\left(\operatorname{Pre}_{k}\right)\right)\right.$.

\subsection{Experiment and comparison}

In order to compare the solutions given by the MILP and by the deterministic algorithm, as the deterministic algorithm does not take into account currently the battery self-discharge and some charge and discharge bounds of the batteries, electrolyzers and fuel cells, we take $\sigma=0$ and the bounds large enough so as not to reach them. The values used for the numerical application are given by Table 3. Figure 10 shows the solution given by the MILP and Figure 11 shows the solution given by the deterministic algorithm. In both cases, the power to be supplied to the data center is the same with Pprod $=255.08 \mathrm{~kW}$. The difference lies in the way energy is allocated to hydrogen and batteries. Indeed, in the case of the MILP, the allocation is less orderly than in the case of the deterministic algorithm. This shows that in this case there is a multitude of optimal solutions.

\section{Consideration of the battery self-discharge}

Currently, the goal is to improve the deterministic algorithm in order to use it. As it stands, the self-discharge of the batteries is not yet taken into account. However, even if this constant does not greatly influence the power supplied to the data center, the way the algorithm manages the energy allocation is different, since the goal is to find the optimal solution.

\begin{tabular}{|c|c|}
\hline Electrolyzers efficiency $\eta_{e z}$ & 0.6 \\
\hline Fuel cells efficiency $\eta_{f c}$ & 0.6 \\
\hline Charge efficiency $\eta_{c h}$ & 0.8 \\
\hline Discharge efficiency $\eta_{d c h}$ & 0.8 \\
\hline Inverter efficiency $\eta_{i n v}$ & 1 \\
\hline Tank efficiency $\eta_{\text {tank }}$ & 1 \\
\hline Max state of charge $S O C \max$ & $100 \%$ \\
\hline Min state of charge $S O C$ min & $0 \%$ \\
\hline Initial state of charge SOCinit & $50 \%$ \\
\hline Capacity $C_{b a t}$ & $1000 \mathrm{~kW}$ \\
\hline Initial hydrogen level LOHinit & $300 \mathrm{~kg}$ \\
\hline Target hydrogen level LOHtarget & $300 \mathrm{~kg}$ \\
\hline Max level $L O H \max$ & $20000 \mathrm{~kg}$ \\
\hline$L H V h_{2}$ & $33.3 \mathrm{kWh} . \mathrm{kg}^{-1}$ \\
\hline$H H V h_{2}$ & $39 k W h . k g^{-1}$ \\
\hline Year & 2004 \\
\hline Days & $200-202$ \\
\hline Time interval $\Delta t$ & $1 h$ \\
\hline Time horizon $\mathcal{H}=K \Delta t$ & $72 h$ \\
\hline Approximation error $\epsilon$ & $10^{-4}$ \\
\hline
\end{tabular}

Table 3: Input data used for the numerical application
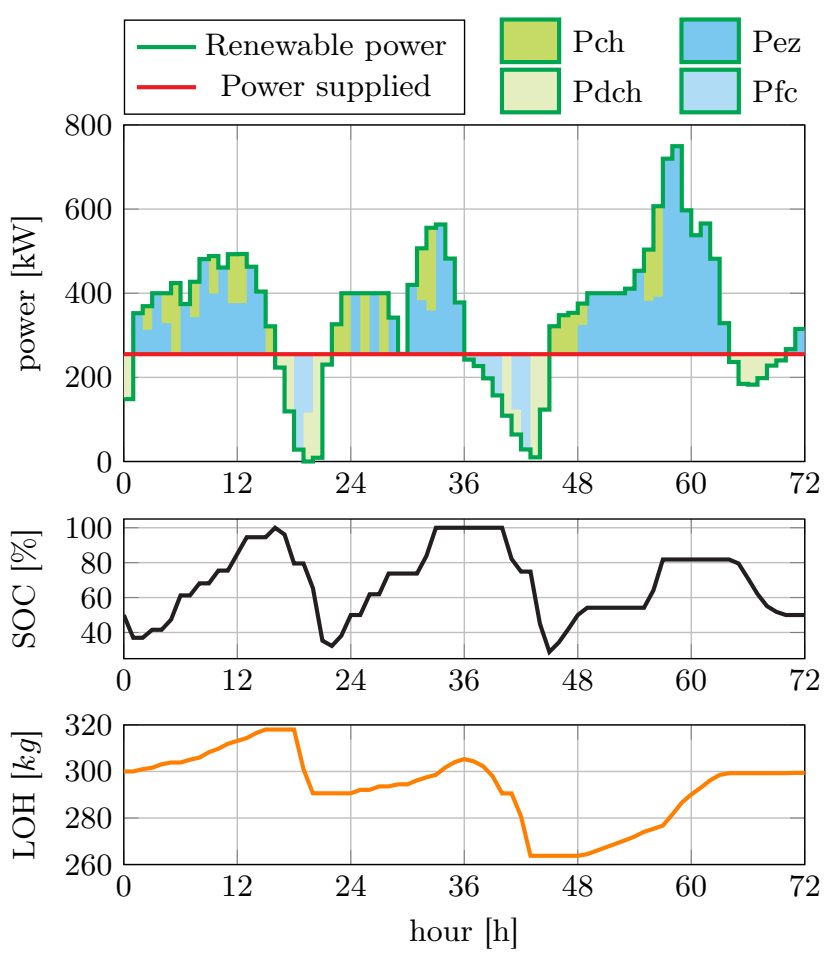

Figure 10: An optimal solution given by the MILP

\subsection{Charge in batteries as late as possible}

If we consider the battery self-discharge, charging as late as possible in the batteries is an optimal process as shown by the Theorem 1

Theorem 1. Charging batteries as late as possible is optimal. 

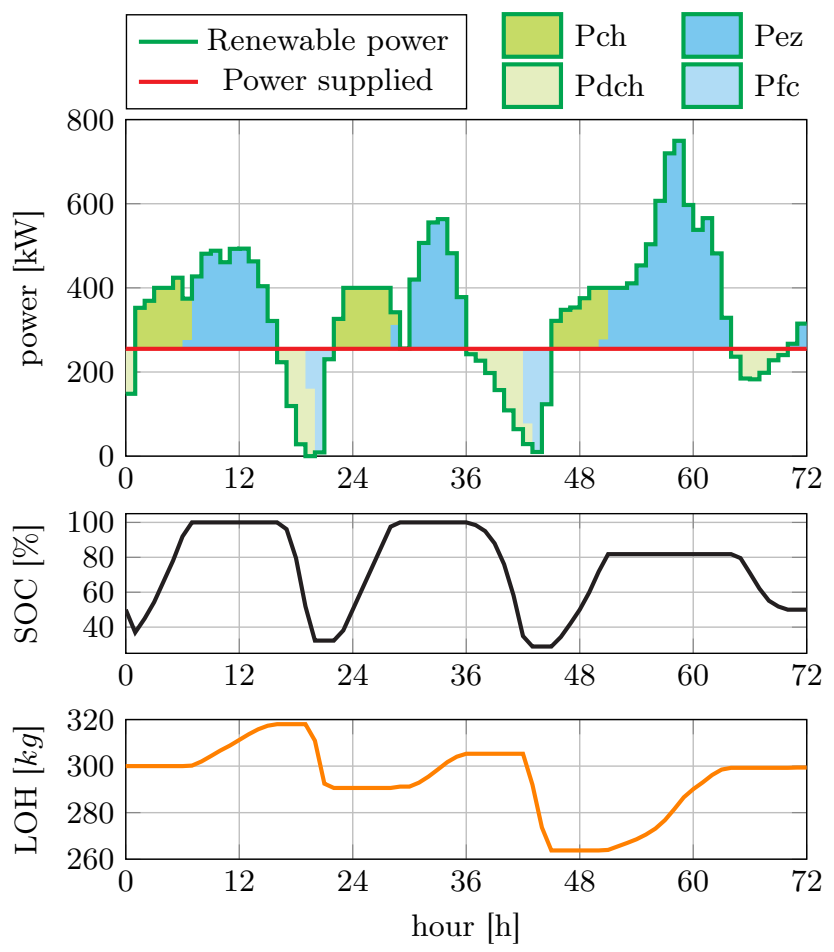

Figure 11: An optimal solution given by the deterministic algorithm

Proof. Let be $0<\sigma<1$ the self-discharge rate, a resolution time $K>1$ in hour and SOCmin $\leq$ SOCinit $\leq$ $S O C \max$ the battery state of charge at hour 0 . Let $P>0$ be a surplus of energy that we charge the batteries at hour 0 and $0<\eta_{c h}<1$ the charge efficiency of the batteries. The batteries are no longer used after charging this amount $P$. Let $S O C_{k}^{b}$ be the battery state of charge at hour $k$ when charged as soon as possible (beginning). So, we have:

$$
S O C_{1}^{b}=\text { SOCinit } \times(1-\sigma)+P \times \eta_{c h}
$$

Then:

$$
S O C_{2}^{b}=S O C_{1}^{b} \times(1-\sigma)
$$

that is to say:

$$
S O C_{2}^{b}=\text { SOCinit } \times(1-\sigma)^{2}+P \times \eta_{c h} \times(1-\sigma)
$$

and by iteration, we have:

$$
S O C_{K}^{b}=\text { SOCinit } \times(1-\sigma)^{K}+P \times \eta_{c h} \times(1-\sigma)^{K-1}
$$

Let $S O C_{k}^{e}$ be the battery state of charge at hour $k$ when charged as late as possible (end). If we load the quantity $\mathrm{P}$ in batteries at the last hour $(k=K)$, we have:

$$
S O C_{K}^{e}=\text { SOCinit } \times(1-\sigma)^{K}+P \times \eta_{c h}
$$

As we can see, we have a difference in batteries at the end of the period $(k=K)$ :

$$
\begin{aligned}
\Delta S O C_{K} & =S O C_{K}^{e}-S O C_{K}^{b} \\
& =P \times \eta_{c h} \times\left(1-(1-\sigma)^{K-1}\right)
\end{aligned}
$$

And we have $\Delta S O C_{K} \geq 0, \forall K \geq 1$. So it is more interesting to charge as late as possible, because we have more energy in batteries at hour $k=K$. This concludes the proof.

Figure 12 highlights this difference by charging batteries at hour 0 and at hour 48 by taking as an example $\sigma=0.01, \eta_{c h}=0.82$, SOCinit $=50 \%$ and $P=300 \mathrm{~kW}$ with $K=48 h$. By choosing to charge the batteries as soon as possible, we obtain $S O C_{48}=46.20 \%$, but by choosing to charge as late as possible, we have $S O C_{48}=55.47 \%$. This rule is very useful if we have charging periods lasting several hours and we need to charge both batteries and hydrogen during these periods. For example, in Figure 11 given by the deterministic algorithm with $\sigma=0$, if we consider $\sigma>0$, the charging period will be rearranged from hour 1 to hour 15 in order to charge as late as possible in batteries, and the rest of the time in hydrogen. Same for the charging period from hour 45 to hour 63 .

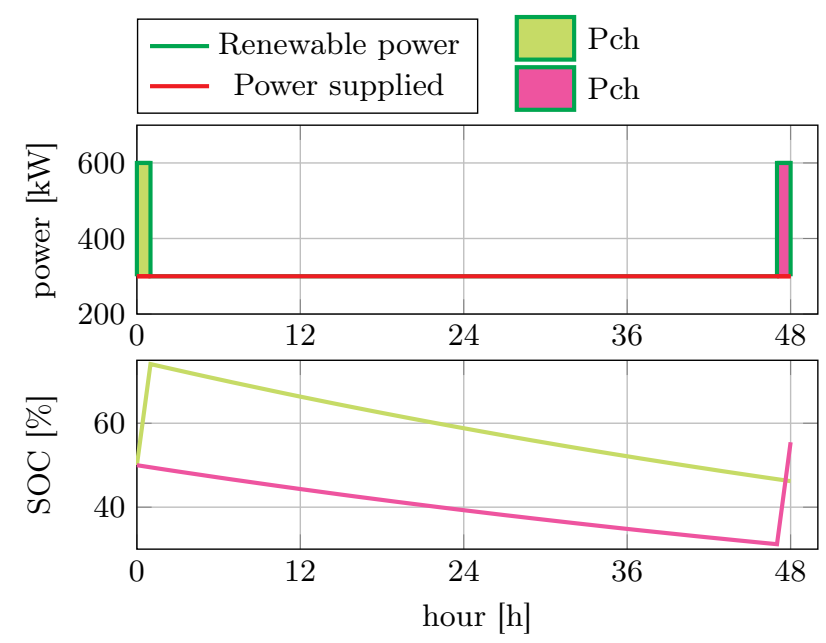

Figure 12: Highlighting the difference in battery state of charge at the end of the day by charging as early as possible (Green) and charging as late as possible (Pink): $S O C_{K}^{e}>S O C_{K}^{b}$.

\subsection{Discharge the batteries as soon as possible}

If we consider the battery self-discharge, discharging batteries as soon as possible is an optimal process as shown by the Theorem 2

Theorem 2. Discharge batteries as soon as possible is optimal.

Proof. Let be the same parameters as in the proof of the Theorem 1. Let $S O C_{k}^{b}$ be the battery state of charge at hour $k$ when discharged as soon as possible. So, we have:

$$
S O C_{1}^{b}=S O C \text { init } \times(1-\sigma)-P \times \eta_{d c h}
$$

then:

$$
S O C_{2}^{b}=\text { SOCinit } \times(1-\sigma)^{2}-P \times \eta_{d c h} \times(1-\sigma)
$$


and by iteration, we have:

$$
S O C_{K}^{b}=\text { SOCinit } \times(1-\sigma)^{K}-P \times \eta_{d c h} \times(1-\sigma)^{K-1}
$$

Let $S O C_{k}^{e}$ be the battery state of charge at hour $k$ when discharged as late as possible. If we discharge the quantity $\mathrm{P}$ from batteries at the last hour $(k=K)$, we have:

$$
S O C_{K}^{e}=\text { SOCinit } \times(1-\sigma)^{K}-P \times \eta_{d c h}
$$

So, the difference comes from the second term. As we can see, if we discharge as soon as possible, we have a difference in batteries at the end of the period $(k=K)$ :

$$
\begin{aligned}
\Delta S O C_{K} & =S O C_{K}^{b}-S O C_{K}^{e} \\
& =P \times \eta_{d c h} \times\left(1-(1-\sigma)^{K-1}\right)
\end{aligned}
$$

And we have $\Delta S O C_{K} \geq 0, \forall K \geq 1$. So it is more interesting to discharge as soon as possible, because we have more energy in batteries. This concludes the proof.

\subsection{Experiment with the MILP}

A new MILP experiment is performed with the same values as in Table 3, but with $\sigma=0.01$ and whose results are presented in Figure 13 .

During the first 24 hours we have to discharge and then charge before a new period of charge and discharge. During the first discharge period, the MILP favors the use of batteries because of their better efficiency and in order to limit the losses due to the self-discharge of the batteries. Then, during the subsequent charging period, the MILP instructs to charge the batteries as late as possible and until the upper limit is reached. The rest of the time is charged using $\mathrm{H}_{2}$. Then, the MILP discharges the batteries as soon as possible, but not completely, because the next charging period must have enough energy to ensure a return to the initial state of charge at the end of the period, all this in order to avoid the use of hydrogen as much as possible.

The next day is approximately the same. Finally, during the last day, the MILP charges the batteries as late as possible and discharges the batteries as soon as possible, and charges in $\mathrm{H}_{2}$ the rest of the time in order to have the targeted hydrogen level. It is sufficient to compare Figure 13 with Figure 10 to realize the change in the energy allocation strategy.

\section{Conclusion and Perspectives}

In this paper, we have proposed an polynomial time algorithm to find the optimal constant and non-constant autonomous renewable power production based on wind and sunlight to supply a data-center disconnected from the classical power grid. In previous studies, a MILP has been written to find constant or non-constant optimal power
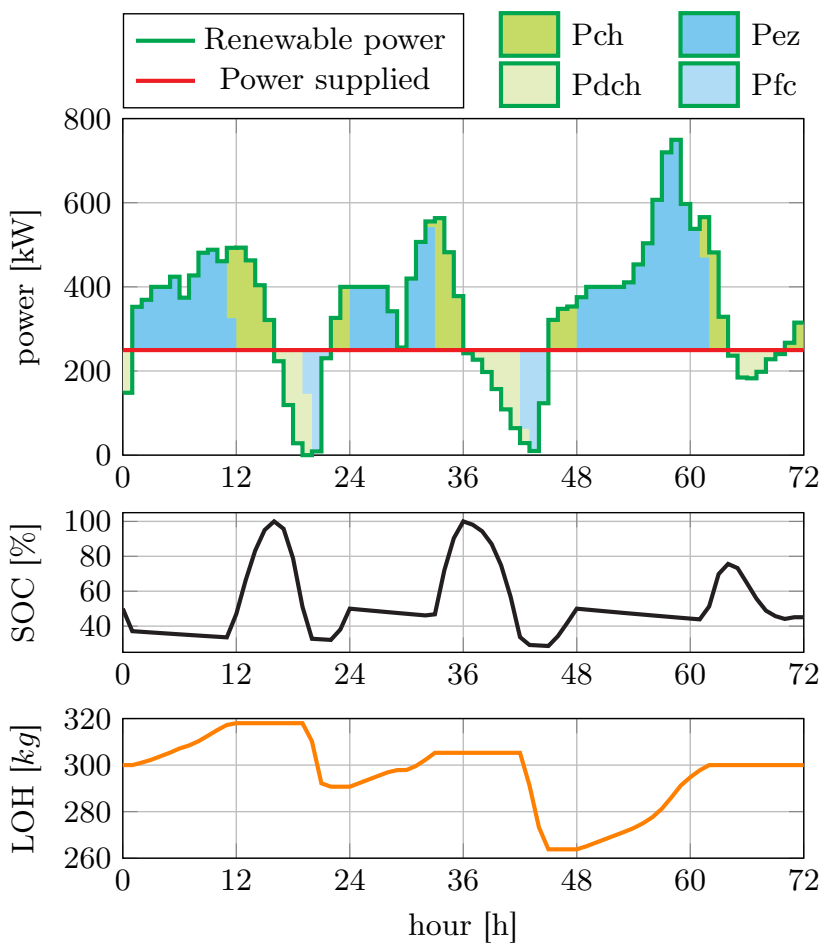

Figure 13: An optimal solution given by the MILP with $\sigma=0.01$

profiles that the electrical part of a data-center can supply considering a power demand and expected weather conditions for the next few days (almost 3 days as in this paper). Even if the solver is efficient, this approach is not scalable. It is why we have proposed an alternative approach based on a deterministic algorithm that helps a binary search algorithm to exhibit optimal power profiles. Experimental results show similar results to those optimally obtained using a MILP solver.

Currently, the proposed algorithm is promising. As an option, we can improve the approach by taking into account bounds of the batteries, electrolyzers and fuel cells. But this limitation does not question the approach. Considering the chosen model and our assumptions, the proposed polynomial time algorithms have been proved as optimal algorithms when considering battery self discharge.

The main advantage of the proposed approach is that it will be now possible to take uncertainty into account in the power supply process. Indeed, this concerns is one of the challenge addressed by the ANR DATAZERO2 project. In this way, the power supply management should become robust and reliable. The presented results are essential to address this challenge as future work within the project.

\section{Acknowledgement}

This work was supported by the ANR DATAZERO2 (contract "ANR-19-CE25-0016") project and by the EIPHI Graduate school (contract "ANR-19-CE25-0016"). 


\section{References}

[1] Internet usage worldwide - statistics \& facts, https://www. statista.com/topics/1145/internet-usage-worldwide/ accessed: 2021-05-28 (2021).

[2] F. Bordage, The environmental footprint of the digital world, GreenIT (2019) 20 URL https : //www . greenit.fr/wp-content/uploads/2019/11/ GREENIT_EENM_etude_EN_accessible.pdf

[3] Greendatanet research project, http://www . greendatanet-project.eu/, accessed: 2021-05-28 (20132016).

[4] J.-M. Pierson, G. Baudic, S. Caux, B. Celik, G. Da Costa, L. Grange, M. Haddad, J. Lecuivre, J.-M. Nicod, L. Philippe, V. Rehn-Sonigo, R. Roche, G. Rostirolla, A. Sayah, P. Stolf, M.T. Thi, C. Varnier, DATAZERO: DATAcenter with Zero Emission and RObust management using renewable energy IEEE Access 7 (2019) (on line). URL http://doi.org/10.1109/ACCESS. 2019.2930368

[5] M. Haddad, J.-M. Nicod, Y. Boubacar Mainassara, L. Rabehasaina, Z. Al Masry, M.-C. Péra, Wind and solar forecasting for renewable energy system using sarima-based model in: 6th International conference on Time Series and Forecasting ( 2019), Gran Canaria, Spain, 2019, pp. 1-15.

URL https: //publiweb.femto-st.fr/tntnet/entries/16409/ documents/author/data

[6] M. Haddad, G. Da Costa, J.-M. Nicod, M.-C. Péra, J.-M. Pierson, V. Rehn-Sonigo, P. Stolf, C. Varnier, Combined it and power supply infrastructure sizing for standalone green data centers Sustainable Computing: Informatics and Systems (2021) 100505 .

URL https : //doi .org/10.1016/j.suscom.2020.100505

[7] M. Haddad, J.-M. Nicod, M.-C. Péra, C. Varnier, Stand-Alone Renewable Power System Scheduling for a Green Data-Center using Integer Linear Programming Version 1, Research report, FEMTO-ST (Mar. 2019).

URL https://hal . archives-ouvertes.fr/hal-02081951

[8] N. A. Baghta, K. P. Aprilianti, D. R. Aryani, F. H. Jufri, A. R. Utomo, Optimization of battery energy storage system (BESS) sizing for solar power plant at remote area, IOP Conference Series: Earth and Environmental Science 599 (2020) 012030. doi:10.1088/1755-1315/599/1/012030.

URL https : //doi.org/10.1088/1755-1315/599/1/012030

[9] P. Colbertaldo, S. B. Agustin, S. Campanari, J. Brouwer, Impact of hydrogen energy storage on california electric power system: Towards 100\% renewable electricity International Journal of Hydrogen Energy 44 (19) (2019) 9558-9576, special Issue on Power To Gas and Hydrogen applications to energy systems at different scales - Building, District and National level. doi:https://doi.org/10.1016/j.ijhydene.2018.11.062 URL https://www.sciencedirect.com/science/article/pii/ S0360319918336449

[10] S. Kharel, B. Shabani, Hydrogen as a long-term large-scale energy storage solution to support renewables Energies 11 (10) (2018). doi:10.3390/en11102825 URL https : //www .mdpi.com/1996-1073/11/10/2825

[11] S. Chalise, A. Golshani, S. R. Awasthi, S. Ma, B. R. Shrestha, L. Bajracharya, W. Sun, R. Tonkoski, Data center energy systems: Current technology and future direction, in: 2015 IEEE Power Energy Society General Meeting, 2015, pp. 1-5. doi:10.1109/PESGM. 2015.7286420

[12] S. O. Amrouche, D. Rekioua, T. Rekioua, Overview of energy storage in renewable energy systems, in: 2015 3rd International Renewable and Sustainable Energy Conference (IRSEC), 2015, pp. 1-6. doi:10.1109/IRSEC. 2015.7454988

[13] S. Teleke, M. E. Baran, S. Bhattacharya, A. Q. Huang, Rulebased control of battery energy storage for dispatching intermittent renewable sources, IEEE Transactions on Sustainable Energy 1 (3) (2010) 117-124. doi:10.1109/TSTE.2010.2061880.

[14] I. Goiri, W. Katsak, K. Le, T. D. Nguyen, R. Bianchini, Designing and managing data centers powered by renewable energy, IEEE Micro 34 (3) (2014) 8-16. doi:10.1109/MM.2014.6
[15] Z. Liu, Y. Chen, C. Bash, A. Wierman, D. Gmach, Z. Wang, M. Marwah, C. Hyser, Renewable and cooling aware workload management for sustainable data centers, in: Proceedings of the 12th ACM SIGMETRICS/PERFORMANCE Joint International Conference on Measurement and Modeling of Computer Systems, SIGMETRICS '12, Association for Computing Machinery, New York, NY, USA, 2012, p. 175-186. doi: $10.1145 / 2254756.2254779$ URL https : //doi .org/10.1145/2254756.2254779

[16] M. Haddad, J.-M. Nicod, M.-C. Péra, Hydrogen infrastructure: data-center supply-refueling station synergy in: 14th IEEE Vehicle Power and Propulsion Conference (VPPC 2017), IEEE, Belfort, France, 2017, p. 6. doi:https://doi.org/10.1109/ VPPC. 2017.8330978

URL https://publiweb.femto-st.fr/tntnet/entries/14329/ documents/author/data

[17] D. Ipsakis, S. Voutetakis, P. Seferlis, F. Stergiopoulos, C. Elmasides, Power management strategies for a stand-alone power system using renewable energy sources and hydrogen storage, International Journal of Hydrogen Energy 34 (16) (2009) 7081-7095, 4th Dubrovnik Conference. doi:https://doi.org/10.1016/j. ijhydene.2008.06.051

URL https://www.sciencedirect.com/science/article/pii/ S0360319908007027

[18] T. Minh-Thuyen, J.-M. Pierson, G. Da Costa, P. Stolf, J.M. Nicod, G. Rostirolla, M. Haddad, Negotiation game for joint it and energy management in green datacenters, Future Generation Computer Systems 110 (2020) 1116 - 1138. doi:10.1016/j.future.2019.11.018

URL https://publiweb.femto-st.fr/tntnet/entries/17263/ documents/author/data

[19] M. Haddad, J. M. Nicod, C. Varnier, M.-C. Péra, Mixed integer linear programming approach to optimize the hybrid renewable energy system management for supplying a standalone data center, in: 2019 Tenth International Green and Sustainable Computing Conference (IGSC), 2019, pp. 1-8. doi: 10.1109/IGSC48788.2019.8957199 